\title{
"We care about your care": A client delivered real time audit and feedback tool of holistic care for men who have sex with men (MSM) attending sexual health services. An audit and reaudit.
}

\author{
Joseph Withers Green, Jocelyn Temu, Jessica Davies, Siobhan Murphy, John McSorley, Gary Brook \\ Department of GUM/HIV Medicine, Central Middlesex Hospital, London, UK
}

\section{Background}

- In 2014 Public Health England produced an action plan to improve the health and well-being of MSM in the UK.*

We used the key domains from this to create a "Checklist for Holistic Care of MSM" for staff to use, and audited it's performance (Audit 1).

-We then redesigned the "Checklist" to enable clients to use it and provide feedback in real time, and re-audited to assess it's acceptability and impact (Audit 2).

\section{Methods}

- Audit 1: 41 MSM <27yrs on their 1st visit January to May 2015

- Audit 2: 207 MSM 15-63yrs on a new visit August 2015 to

Cohort February 2016

- Audit 1: Electronic patient records and staff checklist

- Audit 2: Electronic patient records, staff checklist, and client checklist

- We then performed Fishers exact test to compare the two audits

- The difference in recorded responses between the staff led audit 1 and the staff \& client led audit 2. Additional well-being data reported by clients in the checklist is presented

\section{Results}

Table - Comparison of responses to Audit 1 and Audit 2

\section{Audit 1: Staff Checklist +} Electronic Patient Records

Demographics

Mobile phone number confirmed

Email address given

How are you? Answer recorded

Family aware of sexuality?

Vaccines offered?

Alcohol and drug history?

PEP/PREP awareness recorded?

STI and HIV retesting organized?

Smoking and exercise recorded?

MSM pack given (website and support access information)

Named feedback given

\section{$41 \mathrm{MSM}<27$ years. $1^{\text {st }}$ visit}

$33 / 41(80 \%)$

$29 / 41(70 \%)$

0

0

$41 / 41(100 \%)$

$37 / 41(90 \%)$

$26 / 41(63 \%)$

$20 / 41(49 \%)$

0

$11 / 41(27 \%)$

0

\begin{tabular}{|c|c|}
\hline $\begin{array}{l}\text { Audit 2: Client Checklist }+ \text { Staff Checklist + } \\
\text { Electronic Patient Records }\end{array}$ & $\begin{array}{l}\text { Probability } \\
\text { Value }\end{array}$ \\
\hline \multicolumn{2}{|l|}{207 MSM 15-63 yrs. New visit } \\
\hline $205 / 207(99 \%)$ & $p=0.0001$ \\
\hline $197 / 207(95 \%)$ & $p=0.0001$ \\
\hline \multicolumn{2}{|l|}{$195 / 207(94 \%)$} \\
\hline \multicolumn{2}{|l|}{$199 / 207(96 \%)$} \\
\hline $198 / 207(96 \%)$ & $p=0.04$ \\
\hline $186 / 207(90 \%)$ & $p=1$ \\
\hline $183 / 207(88 \%)$ & $p=0.0002$ \\
\hline $193 / 207(93 \%)$ & $p=0.0001$ \\
\hline \multicolumn{2}{|l|}{$133 / 207(64 \%)$} \\
\hline $179 / 207(86 \%)$ & $p=0.0001$ \\
\hline \multicolumn{2}{|l|}{$206 / 207(99 \%)$} \\
\hline \multicolumn{2}{|c|}{ //206 (15\%) had hazardous alcohol intake and or drug misuse } \\
\hline \multicolumn{2}{|c|}{ orded in EPR, 48(23\%) more disclosed through the client checklist } \\
\hline \multicolumn{2}{|c|}{$2 / 206(30 \%)$ currently smoke } \\
\hline \multicolumn{2}{|c|}{$4 / 206(36 \%)$ take no regular exercise } \\
\hline \multicolumn{2}{|c|}{ nprotected anal sex was associated with smoking $(p=0.02)$, and dru } \\
\hline alcohol misuse $(p=0.004)$ only & \\
\hline
\end{tabular}

- 149/206 (73\%) had self-triaged as Asymptomatic

-46/206 (22\%) had an STI including 5 HIV infections

206/206 (100\%) had venepuncture

- 202/206 (98\%) had triple site testing for bacterial STI

-88/206(43\%) reported unprotected anal sex within 3 months

194/207(94\%) reported being happy

-87/207(42\%) reported "Friends \& Family" unaware of their sexuality
-Being unhappy was associated with drug misuse only $(p=0.01)$.

\section{Conclusion}

- A client led real time audit of care was highly acceptable to clients and staff and was effective in improving the content of client and healthcare worker interactions and documentation

-The checklist complemented STI care focused EPR proformas, significantly improved communication modalities, and was especially valued by staff and clients new to the service

* https://www.gov.uk/government/uploads/system/uploads/attachment_data/file/401005/PHEMSMActionPlan.pdf 